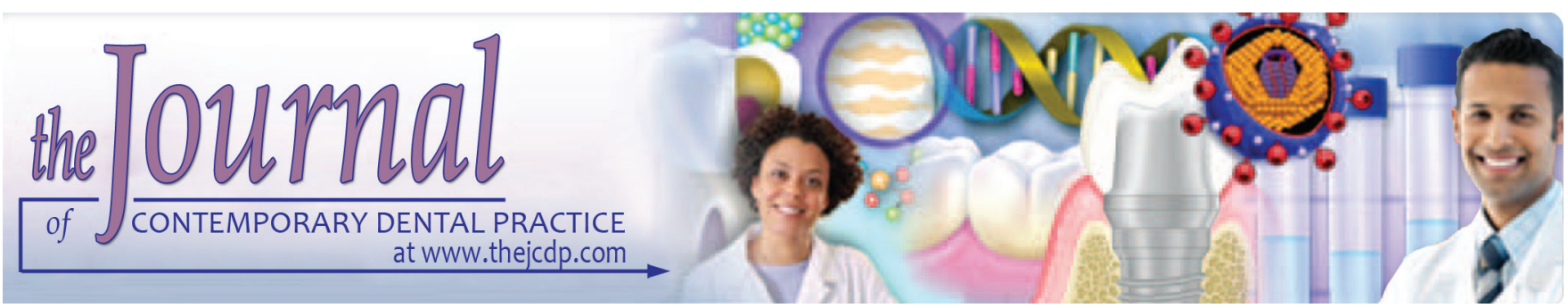

\title{
Use of Interarch Width Ratio to measure Transverse Relationship: A New Method to measure and assess Interarch Discrepancy
}

${ }^{1}$ Waeil Batwa, ${ }^{2}$ Hosam A Baeshen

\begin{abstract}
Aim: The purpose of this study was to assess the arch width, transverse discrepancy, and transverse interarch ratio for class I malocclusion sample, with and without crossbite, in permanent dentition stage.
\end{abstract}

Materials and methods: Records of class I malocclusion patients with minimal crowding and spacing with and without posterior crossbite were selected. Each group consisted of 40 pairs of dental casts (20 males and 20 females). Arch widths were measured for the canine, first, and second premolars, and first permanent molars using the buccal approach. Means and standard deviations (SDs) of dental arch widths were measured for the maxillary and mandibular arches, and the interarch width ratio was calculated.

Results: There was a highly significant difference between the noncrossbite and crossbite groups regarding the maxillary width, $p<0.001$. However, no differences were found between groups for the mandibular widths, $p>0.01$. There were also significant differences between both groups for the intercanine, first and second premolars, and first molar ratios, $p<0.001$.

Conclusion: This new simple method showed that a transverse maxillary-mandibular ratio of $1: 1.1$ is ideal. A ratio less than 1:0.9 will indicate the presence of crossbite.

Clinical significance: The interarch ratio significantly aids in orthodontic treatment planning in patients requiring maxillary expansion and/or surgical cases.

\footnotetext{
${ }^{1}$ Department of Orthodontics, Faculty of Dentistry, King Abdulaziz University, Jeddah, Kingdom of Saudi Arabia

${ }^{2}$ Department of Orthodontics, Faculty of Dentistry, King Abdulaziz University, Jeddah, Kingdom of Saudi Arabia; Al-Farabi Privet Dental and Nursing Schools, Jeddah, Kingdom of Saudi Arabia

Corresponding Author: Waeil Batwa, Department of Orthodontics, Faculty of Dentistry, King Abdulaziz University Jeddah, Kingdom of Saudi Arabia, Phone: +9662565120520 e-mail:wbatwa@kau.edu.sa
}

Keywords: Interarch ratio, Interarch width, Mandibular arch width, Maxillary arch width, Transverse discrepancy.

How to cite this article: Batwa W, Baeshen HA. Use of Interarch Width Ratio to measure Transverse Relationship: A New Method to measure and assess Interarch Discrepancy. J Contemp Dent Pract 2018;19(5):515-520.

Source of support: Nil

Conflict of interest: None

\section{INTRODUCTION}

An accurate evaluation of transverse relationship is critically important in orthodontic diagnosis and treatment planning. This is because orthodontic treatment always aims to achieve an optimum transverse relationship between mandibular and maxillary buccal segments (canine to second permanent molar). Unfortunately, transverse problems, such as dental and skeletal crossbite are quite prevalent, when compared with other mal occlusions; for a growing patient, it can reach up to $23 \%{ }^{1}$ Skeletal crossbite can result from one of the following combinations: narrow maxilla and normal mandible, normal maxilla and wide mandible, and narrow maxilla and wide mandible. ${ }^{2}$ Thus, skeletal crossbite is mainly associated with maxillary constriction (reduction in the absolute maxillary width), ${ }^{3}$ which could be associated with tapered maxillary arch form (V shaped), ${ }^{4}$ deep palatal vault, ${ }^{5}$ and crowded maxillary arch. ${ }^{6}$ Palatally displaced maxillary canine was suggested to influence the maxillary arch width ${ }^{7}$; this was challenged later on, where no statistical difference was found between cases with and without impacted canine in reference to maxillary width. ${ }^{8}$ The etiology of dental crossbite includes, overretention or early loss of primary teeth, crowding, digit sucking habits, ${ }^{9}$ mouth breathing, ${ }^{10}$ and temporomandibular joint problems. 
Several methods have been developed and proposed to assess the transverse relationship of maxillary and mandibular posterior teeth. This includes Howe's approach, ${ }^{11}$ Pont's formula, ${ }^{12}$ transverse discrepancy, ${ }^{3}$ and radiographic method using anteroposterior radiograph. ${ }^{13}$

Howe's approach ${ }^{11}$ correlated the molar teeth width to maxillary basal bone width, and found that in class I cases, the basal arch width is inversely related to molar teeth width in normal occlusion. Pont's formula attempted to relate maxillary arch width to the combined maxillary incisors width; however, they found a poor correlation between the incisors width and maxillary arch width. ${ }^{12}$ The transverse discrepancy, which is the difference between maxillary and mandibular intermolar widths, had been suggested as well. Class I occlusion cases had a mean difference of $0.43 \mathrm{~mm}$ while class II malocclusion cases had a negative difference (less than $0 \mathrm{~mm}$ ), which is indicative of crossbite tendency ${ }^{3}$; the main fall back of the transverse discrepancy is that it is limited to the selected sample (deciduous and early mixed dentition). Furthermore, posteroanterior cephalograms were used to determine the transverse maxillary basal width, and the maxillary width was smaller in both class II and class III subjects when compared with normal. ${ }^{13}$ This technique requires an additional radiographic exposure that could be avoided with the use of model analysis.

The diagnosis of maxillary transverse discrepancies can be challenging. This frequently involves the use of several methods, such as clinical evaluation, dental cast analysis, and radiography. ${ }^{14}$ Posteroanterior cephalograms have been considered a reliable technique to appraise transverse skeletal discrepancies. ${ }^{2}$ However, two-dimensional imaging has technical limitations that may affect the accuracy of landmark placement, which coupled with practitioner lack of skill when identifying landmarks could result in substantial errors. ${ }^{15,16}$ Moreover, thus far, no universal gold standard has been suggested for diagnosing maxillary transverse deficiencies.

Therefore, the purpose of this study was to assess the arch width, transverse discrepancy, ${ }^{3}$ and transverse interarch ratio for class I malocclusion sample, with and without crossbite, in permanent dentition stage.

\section{MATERIALS AND METHODS}

The sample consisted of records of patients with class I malocclusion with minimal crowding. Records were divided into two equal groups based on the presence or absence of transverse discrepancy (posterior crossbite). Each group consisted of 40 pairs of dental casts ( 20 males and 20 females).

The records were for orthodontic patients and were obtained from the patient's database of the Department of
Orthodontics, Faculty of Dentistry. The inclusion criteria were: (1) no history of orthodontic treatment (2) class I molar relationship bilaterally, (3) well-aligned arches with less than $3 \mathrm{~mm}$ of spacing or crowding in either arch. Exclusion criteria for both groups were: (1) history of developmental anomaly and (2) history of trauma to the face, jaws, or teeth. An age- and gender-matched sample was also selected with the same inclusion criteria but with transverse discrepancy.

\section{Measurement of Arch Width}

Sequential maxillary and mandibular casts of the subjects in the test and control groups were measured with digital caliper calibrated to $0.1 \mathrm{~mm}$. Arch widths were measured for the canine, first and second premolars, and first permanent molars based on previously reported methods to record the transverse width buccally ${ }^{17-19}$ Briefly, the intercanine and interpremolar values were recorded at the buccal cervical margin of the tooth from the point of greatest convexity of one tooth to its contralateral in the same arch. For the first permanent intermolar, values were recorded at the junction of the cervix with the cervical extension of the buccal developmental groove (Fig. 1). Means and SDs of dental arch widths were measured for the maxillary and mandibular arches and the interarch width ratio was calculated.

All measurements were made by one investigator in order to reduce systematic error. Measurements were repeated on 15 sets of dental casts 2 weeks later, and the intraexaminer repeatability between the values of the first and second readings was assessed. Intrareliability test (Cronbach's alpha) was 0.99, indicating an excellent level of reliability.

Intraclass correlation coefficient for model measurements, based on two measurements, 1 week apart, for each of the 4 widths from 10 subjects, ranged from 0.91 to 0.99 .

\section{Statistical Analysis}

Data were analyzed using the Statistical Package for the Social Sciences (IBM SPSS Statistics for Mac, Version 20, Armonk, NY: IBM Corp, USA). The results are shown as mean \pm SD. To test the normality assumption, ShapiroWilk test was used; the results showed that the data were normally distributed. Bivariate comparisons were performed using independent sample t-tests. The univariate analysis of variance was used to calculate the differences between groups and gender for age. The difference was considered significant if the p-value was less than 0.01 to guard against type I error.

\section{RESULTS}

Univariate analysis of variance showed that there were no differences among the studied groups and gender for age, $p>0.05$ (Table 1 ). 

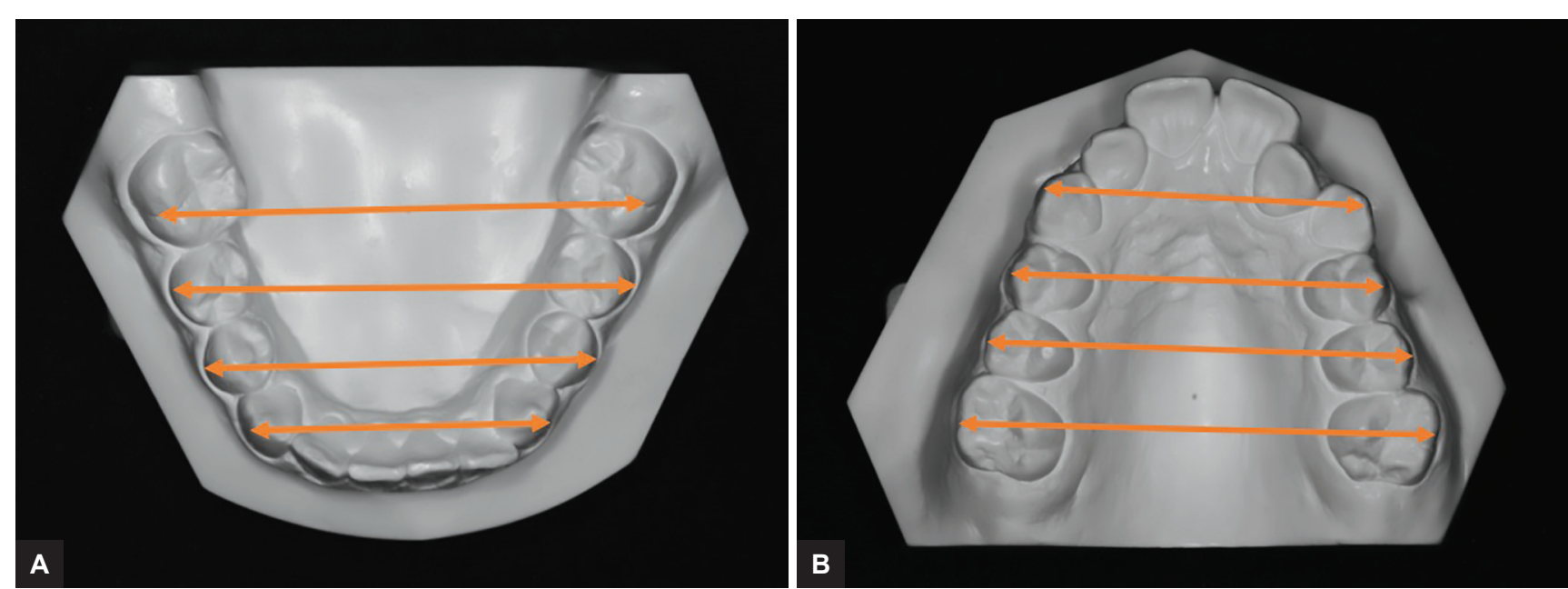

Figs $1 \mathrm{~A}$ and $\mathrm{B}$ : The intercanine and interpremolar values were recorded at the buccal cervical margin of the tooth from the point of greatest convexity of one tooth to its contralateral in the same arch. For intermolar width, it was recorded at the junction of the cervix with the cervical extension of the buccal developmental groove

Table 1: Distribution and comparisons between the noncrossbite and crossbite groups for age

\begin{tabular}{llll}
\hline Group & $\begin{array}{l}\text { Males } \\
(n=40)\end{array}$ & $\begin{array}{l}\text { Females } \\
(n=40)\end{array}$ & $p$-value \\
\hline Noncrossbite $(\mathrm{n}=20)$ & $18.55 \pm 3.39$ & $18.50 \pm 2.93$ & 0.96 \\
Crossbite $(\mathrm{n}=20)$ & $17.00 \pm 4.70$ & $18.3 \pm 5.58$ & 0.43 \\
p-value & 0.22 & 0.88 & \\
\hline
\end{tabular}

Data are presented as mean $( \pm \mathrm{SD})$

Table 2: Bivariate comparisons for the maxillary widths between the noncrossbite and crossbite groups

\begin{tabular}{llll}
\hline & \multicolumn{2}{c}{ Group } & \\
\cline { 2 - 3 } $\begin{array}{l}\text { Maxillary } \\
\text { widths }\end{array}$ & $\begin{array}{l}\text { Noncrossbite } \\
(n=40)\end{array}$ & Crossbite $(n=40)$ & $p$-value \\
\hline Intercanine & $38.37 \pm 1.94(6.76)$ & $31.96 \pm 1.50(3.71)$ & $<0.001$ \\
Interfirst & $45.55 \pm 2.11(7.79)$ & $38.28 \pm 2.46(7.31)$ & $<0.001$ \\
premolar & & & \\
Intersecond & $50.22 \pm 2.10(6.17)$ & $42.59 \pm 3.03(10.10)$ & $<0.001$ \\
premolar & & & \\
Intermolar & $56.28 \pm 2.40(8.20)$ & $49.51 \pm 2.32(8.53)$ & $<0.001$ \\
\hline
\end{tabular}

Data are presented as mean $( \pm \mathrm{SD})$

There was a highly significant difference between the noncrossbite and crossbite groups regarding the maxillary width, $\mathrm{p}<0.001$. The maxillary width ranged from 38.37 $( \pm 1.94)$ in the intercanine width to $56.28( \pm 2.40)$ in the intermolar width for the noncrossbite group. However, in the crossbite group, the maxillary width was significantly less, ranging from $31.96( \pm 1.50)$ in the intercanine width to $49.51( \pm 2.32)$ in the intermolar width (Table 2). Overall, the maxillary width was found to be 5 to $6 \mathrm{~mm}$ less in the crossbite group for the intercanine, interpremolar, and intermolar widths.

In contrast to the maxillary widths, the mandibular widths were not significantly different between both groups ( $p>0.05)$. It ranged from $30.91( \pm 2.37)$ in the intercanine width to $53.06( \pm 2.82)$ in the intermolar width for the
Table 3: Bivariate comparisons for the mandibular widths between the noncrossbite and crossbite groups

\begin{tabular}{llll}
\hline Mandibular & \multicolumn{2}{c}{ Group } & \\
\cline { 2 - 3 } widths & Noncrossbite $(n=40)$ & Crossbite $(n=40)$ & $p$-value \\
\hline Intercanine & $30.91 \pm 2.37(7.98)$ & $30.70 \pm 1(2.56)$ & 0.61 \\
Interfirst & $40.04 \pm 2.25(8.01)$ & $38.86 \pm 2.39(7.74)$ & 0.03 \\
premolar & & & \\
Intersecond & $45.96 \pm 2.49(8.54)$ & $45.48 \pm 3.04(7.78)$ & 0.44 \\
premolar & & & \\
Intermolar & $53.06 \pm 2.82(9.91)$ & $53.35 \pm 2.73(8.92)$ & 0.64 \\
\hline
\end{tabular}

Data are presented as mean $( \pm \mathrm{SD})$

Table 4: Bivariate comparisons between maxillary and mandibular width for the noncrossbite and crossbite groups

\begin{tabular}{llcr}
\hline & \multicolumn{2}{c}{ Group } & \\
\cline { 2 - 3 } $\begin{array}{l}\text { Max-Min } \\
\text { difference }\end{array}$ & $\begin{array}{l}\text { Noncrossbite } \\
(n=40)\end{array}$ & Crossbite $(n=40)$ & $p$-value \\
\hline Canines & $7.46 \pm 1.40(4.71)$ & $1.26 \pm 1.97(5.67)$ & $<0.001$ \\
$\begin{array}{l}\text { First } \\
\text { premolars }\end{array}$ & $5.50 \pm 1.49(5.19)$ & $-0.58 \pm 3.80(10.26)$ & $<0.001$ \\
$\begin{array}{l}\text { Second } \\
\text { premolars }\end{array}$ & $4.26 \pm 1.54(5.39)$ & $-2.88 \pm 2.87(9.15)$ & $<0.001$ \\
First molars & $3.22 \pm 1.26(4.02)$ & $-3.84 \pm 2.68(8.05)$ & $<0.001$ \\
\hline
\end{tabular}

Data are presented as mean $( \pm S D)$

noncrossbite group, which was very similar to the crossbite group that ranged from $30.70( \pm 1.0)$ in the intercanine width to $53.35( \pm 2.73)$ in the intermolar width (Table 3).

The transverse discrepancy was significantly different between the two groups, where a negative difference always indicates a crossbite, for the premolars and the first molar. The canine difference was positive for the both groups; however, it was smaller in the crossbite group than in the noncrossbite group, 7.46 and $1.26 \mathrm{~mm}$ respectively (Table 4$)$.

When comparing the difference in the interwidth ratio between noncrossbite and crossbite groups, Table 5 
Table 5: Transverse ratio between maxillary and mandibular width as measured on canines, first premolar, second premolar, and first molar

\begin{tabular}{llll}
\hline \multirow{2}{*}{$\begin{array}{l}\text { Max-Min } \\
\text { ratio }\end{array}$} & \multicolumn{2}{c}{ Group } & \\
\cline { 2 - 3 } & Noncrossbite $(n=40)$ & Crossbite $(n=40)$ & $p$-value \\
\hline Canine & $1.20( \pm 0.09)(0.42)$ & $1.04( \pm 0.06)(0.18)$ & $<0.001$ \\
$\begin{array}{l}\text { First } \\
\text { premolar }\end{array}$ & $1.10( \pm 0.09)(0.49)$ & $0.98( \pm 0.09)(0.25)$ & $<0.001$ \\
$\begin{array}{l}\text { Second } \\
\text { premolar })\end{array}$ & $1.05( \pm 0.07)(0.30)$ & $0.94( \pm 0.06)(0.19)$ & $<0.001$ \\
$\begin{array}{l}\text { First } \\
\text { molar }\end{array}$ & $1.03( \pm 0.06)(0.21)$ & $0.92( \pm 0.04)(0.14)$ & $<0.001$ \\
\hline
\end{tabular}

Data are presented as means $( \pm S D)$

shows that the results were significant, $\mathrm{p}<0.001$. A ratio of more than 1:1.1 indicates an absence of crossbite in the noncrossbite group, while a ratio of less than 0.9 always indicates a crossbite in the crossbite group. The ratio was found to be smaller between the posterior teeth, and hence, molars and second premolars had a smaller ratio than the canine and first premolars (Table 5).

\section{DISCUSSION}

When diagnosing maxillary transverse discrepancies, the commonly used methods by clinicians include a combination of clinical and dental cast assessments that evaluates the presence of crossbite, degree of crowding, arch width measurements, perceived buccolingual inclination of teeth, and the shape and height of the palatal vault. $^{20-22}$

Transverse maxillary deficiency is evident in several malocclusions, class I, ${ }^{23}$ class II, ${ }^{3,13}$ and class III. ${ }^{13}$ It had been found that crowded class I cases had smaller maxillary width than noncrowded cases. ${ }^{23}$ In class II malocclusion, it was mainly linked to reduced transverse maxillary width, ${ }^{3}$ with no mandibular width involvement, ${ }^{13}$ which is similar to the findings of this study where maxillary widths were significantly reduced in the crossbite group when compared with the noncrossbite group, while the measured mandibular width did not reflect this, as mandibular widths were very close for both groups. This discrepancy between maxillary and mandibular width is not easy to explain. One way to look at this is as a disturbance in the transverse arch width growth pattern. ${ }^{24}$

The reduced maxilla width in the current sample was calculated dentally by measuring the interarch width for the posterior teeth. Although it cannot be claimed that the reduced maxillary width is purely skeletal, the current results showed a reduction in the maxillary width, which could be attributed to dental and/or skeletal involvement. This is similar to the findings of Franchi and Baccetti, ${ }^{13}$ regarding class II malocclusion where width reduction was found in the dental and skeletal base. Unfortunately, transverse deficiency is not an isolated problem; it could be associated with class III malocclusion, which in turn is associated with other problems, such as increased mandibular length, reduced maxillary length, and increased vertical proportions, especially the lower anterior face height. ${ }^{25}$ The maxillary transverse deficiency has been associated with vertical problems, such as anterior open bite, and subjects with anterior open bite showed transverse deficiencies in the zygomatic region, in the maxilla, and in the mandible. ${ }^{26}$ In an interesting longitudinal study, the mandibular plane angle (vertical facial pattern) was linked to maxillary width, and it has been found that at young age (6 years), the high-angle patients had narrower maxillary and mandibular widths than the low-angle patients, and this trend continued until age $18 .^{27}$

Regarding the transverse discrepancy, our findings are in agreement with those of Baccetti et $\mathrm{al}^{3}{ }^{3}$ as both studies indicate that a negative discrepancy will always suggest the presence in crossbite. Although our sample was in permanent dentition, a discrepancy of $-3.84( \pm 2.68)$ was recorded on the molar region, which is quite similar to Baccetti's finding that was recorded at the mixed dentition stage $(-4.09 \pm 3.03)$.

The ratio of mandibular-maxillary width was suggested in this study as a simple method to harmonize the maxillary and mandibular widths. The current results indicate that a ratio of more than 1:1.1 will always indicate an absence of crossbite when applied to all buccal segments (canine, premolars, and first molars). Having said that, it was noticed that the ratio is not constant, as it gets smaller toward the most posterior teeth, which could be attributed to the fact that mandibular width does not follow the same pattern as maxillary width, as it heads posteriorly. On the contrary, a ratio of less than 1:0.9 was associated with crossbite, which suggests that any transverse arch treatment should achieve a ratio of more than 1:0.9.

The presence of crossbite may require an early interceptive treatment. ${ }^{1}$ This treatment should be directed to the maxillary arch, ${ }^{28-30}$ as it is usually associated with a transverse deficiency. In growing patients, this could be carried by rapid or slow palatal expander, ${ }^{31}$ Quad Helix or fixed appliance, while in adult patients, it might require surgically assisted expansion. ${ }^{32}$ In both cases, we suggest to maintain a maxillary-mandibular ratio of 1:1.1 at least.

The suggested ratio is of quite importance when planning the preorthodontic treatment of class III surgical cases, where these cases usually require transverse dental and/or skeletal decompensation. As we mentioned earlier, class III cases are usually associated with crossbite. ${ }^{25}$ This crossbite appears as a result of maxillary 
transverse deficiency, or as a result of mandibular/ maxillary sagittal position discrepancy, where a more posterior position of the maxilla or anterior position of the mandible will result in this crossbite. ${ }^{33}$ This happens because the mandible is wider posteriorly than the maxilla, and for such cases, predicting the amount of maxillary expansion is quite difficult, as the orthodontist always aims at expansion that is enough to avoid any crossbite development postsurgery. Applying the inter arch ratio to these cases makes it easier to predict how much expansion is needed, as it gives the clinician a numerical value to work for, which is a ratio of 1:1.1 between mandible and maxilla.

\section{CONCLUSION}

This new simple method would aid in estimating the amount of maxillary expansion, where a transverse maxillary-mandibular ratio of 1:1.1 is desirable. A ratio of less than 0.9 and a negative transverse discrepancy will always indicate the presence of crossbite. These findings should significantly aid in orthodontic treatment planning in patients requiring maxillary expansion, particularly in surgical cases.

\section{REFERENCES}

1. Kurol J, Berglund L. Longitudinal study and cost-benefit analysis of the effect of early treatment of posterior cross-bites in the primary dentition. Eur J Orthod 1992 Jun;14(3):173-179.

2. Betts NJ, Vanarsdall RL, Barber HD, Higgins-Barber K, Fonseca RJ. Diagnosis and treatment of transverse maxillary deficiency. Int J Adult Orthodon Orthognath Surg 1995 Feb;10(2):75-96.

3. Baccetti T, Franchi L, McNamara JA Jr, Tollaro I. Early dentofacial features of Class II malocclusion: a longitudinal study from the deciduous through the mixed dentition. Am J Orthod Dentofacial Orthop 1997 May;111(5):502-509.

4. Howe RP, McNamara JA Jr, O'Connor KA. An examination of dental crowding and its relationship to tooth size and arch dimension. Am J Orthod 1983 May;83(5):363-373.

5. Leonardi R, Sicurezza E, Cutrera A, Barbato E. Early posttreatment changes of circumaxillary sutures in young patients treated with rapid maxillary expansion. Angle Orthod 2011 Jan;81(1):36-41.

6. McNamara JA. Maxillary transverse deficiency. Am J Orthod Dentofacial Orthop 2000 May;117(5):567-570.

7. McConnell TL, Hoffman DL, Forbes DP, Janzen EK, Weintraub NH. Maxillary canine impaction in patients with transverse maxillary deficiency. ASDC J Dent Child 1996 May-Jun;63(3):190-195.

8. Langberg BJ, Peck S. Adequacy of maxillary dental arch width in patients with palatally displaced canines. Am J Orthod Dentofacial Orthop 2000 Aug;118(2):220-223.

9. Larsson E. The effect of dummy-sucking on the occlusion: a review. Eur J Orthod 1986 May;8(2):127-130.

10. Bresolin D, Shapiro PA, Shapiro GG, Chapko MK, Dassel S. Mouth breathing in allergic children: Its relationship to dentofacial development. Am J Orthod 1983 Apr;83(4): 334-340.
11. Howes AE. Model analysis for treatment planning. Am J Orthod 1952 Mar;38(3):183-207.

12. Joondeph DR, Riedel RA, Moore AW. Pont's index: a clinical evaluation. Angle Orthod 1970 Apr;40(2):112-118.

13. Franchi L, Baccetti T. Transverse maxillary deficiency in Class II and Class III malocclusions: a cephalometric and morphometric study on postero-anterior films. Orthod Craniofac Res 2005 Feb;8(1):21-28.

14. Suri L, Taneja P. Surgically assisted rapid palatal expansion: a literature review. Am J Orthod Dentofacial Orthop 2008 Feb;133(2):290-302.

15. Leonardi R, Annunziata A, Caltabiano M. Landmark identification error in posteroanterior cephalometric radiography. A systematic review. Angle Orthod 2008 Jul;78(4):761-765.

16. Major PW, Johnson DE, Hesse KL, Glover KE. Landmark identification error in posterior anterior cephalometrics. Angle Orthod 1994 Dec;64(6):447-454.

17. McDougall PD, McNamara JA Jr, Dierkes JM. Arch width development in Class II patients treated with the Frankel appliance. Am J Orthod 1982 Jul;82(1):10-22.

18. Staley RN, Stuntz WR, Peterson LC. A comparison of arch widths in adults with normal occlusion and adults with class II, Division 1 malocclusion. Am J Orthod 1985 Aug;88(2):163-169.

19. Huth J, Staley RN, Jacobs R, Bigelow H, Jakobsen J. Arch widths in class II-2 adults compared to adults with class II-1 and normal occlusion. Angle Orthod 2007 Sep;77(5): 837-844.

20. Sawchuk D, Currie K, Vich ML, Palomo JM, Flores-Mir C. Diagnostic methods for assessing maxillary skeletal and dental transverse deficiencies: a systematic review. Korean J Orthod 2016 Sep;46(5):331-342.

21. GoldenbergDC,AlonsoN, GoldenbergFC,GebrinES,AmaralTS, Scanavini MA, Ferreira MC. Using computed tomography to evaluate maxillary changes after surgically assisted rapid palatal expansion. J Craniofac Surg 2007 Mar;18(2): 302-311.

22. Lemieux G, Carey JP, Flores-Mir C, Secanell M, Hart A, Dietrich $\mathrm{N}$, Lagravère-Vich MO. Three-dimensional cephalometric superimposition of the nasomaxillary complex. Am J Orthod Dentofacial Orthop 2014 Dec;146(6):758-764.

23. Poosti M, Jalali T. Tooth size and arch dimension in uncrowded versus crowded Class I malocclusions. J Contemp Dent Pract 2007 Mar;8(3):45-52.

24. Hesby RM, Marshall SD, Dawson DV, Southard KA, Casko JS, Franciscus RG, Southard TE. Transverse skeletal and dentoalveolar changes during growth. Am J Orthod Dentofacial Orthop 2006 Dec;130(6):721-731.

25. Guyer EC, Ellis EE 3rd, McNamara JA Jr, Behrents RG. Components of class III malocclusion in juveniles and adolescents. Angle Orthod 1986 Jan;56(1):7-30.

26. Ballanti F, Franchi L, Cozza P. Transverse dentoskeletal features of anterior open bite in the mixed dentition. Angle Orthod 2009 Aug;79(4):615-620.

27. Wagner DM, Chung CH. Transverse growth of the maxilla and mandible in untreated girls with low, average, and high MP-SN angles: a longitudinal study. Am J Orthod Dentofacial Orthop 2005 Dec;128(6):716-723; quiz 801.

28. Garrett BJ, Caruso JM, Rungcharassaeng K, Farrage JR, Kim JS, Taylor GD. Skeletal effects to the maxilla after rapid maxillary expansion assessed with cone-beam computed tomography. Am J Orthod Dentofacial Orthop 2008 Jul;134(1):8-9. 
29. Lagravere MO, Major PW, Flores-Mir C. Long-term skeletal changes with rapid maxillary expansion: a systematic review. Angle Orthod 2005 Nov;75(6):1046-1052.

30. Lagravere MO, Carey J, Heo G, Toogood RW, Major PW. Transverse, vertical, and anteroposterior changes from bone-anchored maxillary expansion vs traditional rapid maxillary expansion: a randomized clinical trial. Am J Orthod Dentofacial Orthop 2010 Mar;137(3):304.e1-304.e12; discussion 304-305.
31. Altug Atac AT, Karasu HA, Aytac D. Surgically assisted rapid maxillary expansion compared with orthopedic rapid maxillary expansion. Angle Orthod 2006 May;76(3):353-359.

32. Koudstaal MJ, Poort LJ, van der Wal KG, Wolvius EB, PrahlAndersen B, Schulten AJ. Surgically assisted rapid maxillary expansion (SARME): a review of the literature. Int J Oral Maxillofac Surg 2005 Oct;34(7):709-714.

33. Ellis E 3rd, McNamara JA Jr. Components of adult Class III malocclusion. J Oral Maxillofac Surg 1984 May;42(5):295-305. 